\title{
Ruptured liver abscess presenting as pneumoperitoneum caused by Klebsiella pneumoniae: a case report
}

\author{
Thuong Pham Van', Son Vu Ngoc ${ }^{1}$, Ngoc Anh Nguyen Hoang ${ }^{1}$, Doan Hoang Huu ${ }^{1}$ and \\ Tung Anh Dinh Duong ${ }^{2^{*}}$ (D)
}

\begin{abstract}
Background: Spontaneous gas-forming pyogenic liver abscess (GFPLA) is a rare complication with a high fatality rate in spite of aggressive management. Clinical spectrum of GFPLA can mimic hollow viscus perforation as it usually accompanied by pneumoperitoneum and peritonitis. Up to now, GFPLA has not been well studied in Vietnam.

Case presentation: We reported here a case with pneumoperitoneum caused by ruptured liver abscess in a 41 -yearold man with a history of treated duodenal ulcer and uncontrolled type II diabetes mellitus. He had an epigastric pain associated with a high fever. Patient was diagnosed peritonitis and pneumoperitoneum presumed to be secondary to perforation of a hollow viscus and subjected to emergency laparotomy. We did not find any gastrointestinal perforation. Surprisingly, we detected a $4 \mathrm{~cm} \times 4 \mathrm{~cm}$ pus-containing abscess in the left liver lobe of the liver. The abscess was ruptured. Pus was running into abdominal cavity through one hole. The abscess and abdominal cavities were cleaned up and abscess and abdominal drainages were performed. K. pneumoniae was isolated from culture of the abscess. The histopathological examination of the abscess did not yield any evidence of malignancy. Blood glucose levels were controlled. Antibiotic therapy was used according to antibiogram. A reassessment chest $X$-ray showed no air-fluid level or subdiaphragmatic air by the hospital day 14 . Patient eventually made a full recovery and was discharged home 23 days after the operation.

Conclusions: Ruptured GFPLA is a life-threatening complication. It is usually accompanied by peritonitis and pneumoperitoneum and can imitate hollow viscous perforation. In these cases, CT scan should be performed whenever it is possible to make a correct diagnosis. When the abscess has small size, partial hepatectomy might not be necessary and could be replaced by a careful cleaning and drainage of the abscess. Patient could show a good postoperative recovery following an appropriate antibiotic therapy.
\end{abstract}

Keywords: Pneumoperitoneum, Ruptured liver abscess, Klebsiella pneumoniae, Case report

\footnotetext{
* Correspondence: ddtanh@hpmu.edu.vn

${ }^{2}$ Pediatrics Department, Haiphong University of Medicine and Pharmacy, Haiphong, Vietnam

Full list of author information is available at the end of the article
}

(c) The Author(s). 2020 Open Access This article is licensed under a Creative Commons Attribution 4.0 International License, which permits use, sharing, adaptation, distribution and reproduction in any medium or format, as long as you give appropriate credit to the original author(s) and the source, provide a link to the Creative Commons licence, and indicate if changes were made. The images or other third party material in this article are included in the article's Creative Commons licence, unless indicated otherwise in a credit line to the material. If material is not included in the article's Creative Commons licence and your intended use is not permitted by statutory regulation or exceeds the permitted use, you will need to obtain permission directly from the copyright holder. To view a copy of this licence, visit http://creativecommons.org/licenses/by/4.0/. The Creative Commons Public Domain Dedication waiver (http://creativecommons.org/publicdomain/zero/1.0/) applies to the data made available in this article, unless otherwise stated in a credit line to the data. 


\section{Background}

Pyogenic liver abscess (PLA) is important cause of hospitalization and life threatening disease in low-middle income countries $[6,18]$. Spontaneous gas-forming pyogenic liver abscess (GFPLA) is a rare complication with a high fatality rate in spite of aggressive management [3]. Clinical spectrum of GFPLA can mimic hollow viscus perforation as it usually accompanied by pneumoperitoneum and peritonitis [7]. Previous studies showed that E. coli and $K$. pneumoniae are the most common pathogens isolated in pyogenic liver abscess [10].

GFPLA is uncommon in western countries but often reported in Asian countries such as Taiwan and South Korea [5, 10]. Recently, ruptured liver abscess has received attention of clinicians and researchers in Vietnam $[4,17]$. However, further studies are required in order to elucidate the general states and characteristics of GFPLA in this country where there is still a high percentage of low resource medical settings. Here, we reported a case of pneumoperitoneum due to ruptured pyogenic liver abscess caused by Klebsiella pneumoniae.

\section{Case presentation}

We present a case of a 41-years-old man living in a rural area with a history of treated duodenal ulcer and uncontrolled type II diabetes mellitus. Five days before the hospital admission, this patient had an epigastric pain associated with a high fever (up to $39.5^{\circ} \mathrm{C}$ ). Four hours before the hospitalization, his epigastric pain was seriously and dramatically increased. A physical examination on admission to the emergency department revealed high temperature of $39{ }^{\circ} \mathrm{C}$ and generalized rigidity of the abdominal wall, suggesting a peritonitis. His heart rate was 109 beats/min and his blood pressure were $120 / 80 \mathrm{mmHg}$. There was not a clear clinical anemia or jaundice. His white blood cell count was
$19.1 \times 10^{9} / \mathrm{L}$ and the percentage of neutrophils was $85.3 \%$. Other laboratory results were as follows: serum pro-calcitonin level, $17.73 \mathrm{ng} / \mathrm{ml}$; serum glucose level, $14.7 \mathrm{mmol} / \mathrm{L}$; serum bilirubin level, $37.6 \mathrm{mmol} / \mathrm{L}$; serum aspartate aminotransferase level, $51 \mathrm{U} / \mathrm{L}$ and serum alanine aminotransferase level, $87 \mathrm{U} / \mathrm{L}$.

Both of the chest and abdominal X-ray showed bilateral subdiaphragmatic air, indicating pneumoperitoneum (Fig. 1). Consistently, ultrasound scan of the abdomen was conducted and detected free intraperitoneal air and fluid. It was hard to evaluate liver tissue due to the presence of intraperitoneal air and no hypoechoic foci was detected in the liver by this method. Unfortunately, computed tomography (CT) of the abdomen was not available by the time of the admission.

Patient was diagnosed peritonitis and pneumoperitoneum presumed to be secondary to perforation of a hollow viscus and treated for septic shock with intravenous fluid and broad-spectrum antibiotic. He was subjected to emergency laparotomy. Based on his previously reported duodenal ulcer history, we carefully checked and did not find any gastrointestinal perforation. Surprisingly, we detected a $4 \mathrm{~cm} \times 4 \mathrm{~cm}$ pus-containing abscess in the left liver lobe of the liver. The abscess was ruptured. Pus was running into abdominal cavity through one hole. At the end of the operation, $80 \mathrm{ml}$ of turbid pus was drained from the subphrenic and subhepatic spaces. We carefully checked and did not find any underlying disease of the biliary tract. We concluded that the pneumoperitoneum resulted from spontaneous rupture of the hepatic abscess in the left liver. We placed abdominal drains in the abscess cavity and the subhepatic area. K. pneumoniae was isolated from culture of the abscess. The histopathological examination of the abscess did not yield any evidence of malignancy. Blood glucose levels were controlled. Antibiotic therapy was used according to
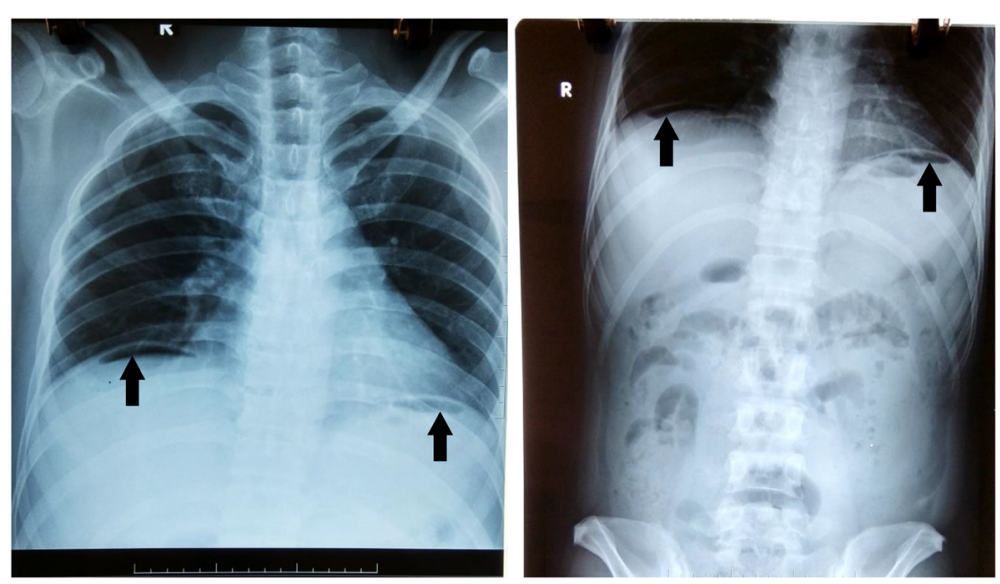

Fig. 1 Gas under both domes of diaphragm on radiograph. Routine preoperative X-ray taken on admission showed free gas under both domes of diaphragm (arrows) 
antibiogram (piperacilin and tazobactam). A reassessment chest X-ray showed no air-fluid level or subdiaphragmatic air by the hospital day 14 . The patient eventually made a full recovery without any complication and was discharged home 23 days after the operation.

\section{Discussion and conclusions}

Pyogenic liver abscess (PLA) is a common infectious disease worldwide relating to a mortality rate ranging between 15 and 19\% [15, 18]. Gas-forming pyogenic liver abscess (GFPLA) remains one of the most dangerous complication with a high fatality rate in spite of aggressive management [10]. Klebsiella pneumoniae is considered to surpass Escherichia coli (E. coli) to become the major pathogen of pyogenic liver abscesses, especially in GFPLA and in patients with diabetic mellitus (DM) $[9,10]$. Here, we reported a case of Klebsiella pneumoniae-induced gasforming pyogenic liver abscess with uncontrolled DM history.

CT-Scan plays a key role in the diagnosis of gasforming pyogenic liver abscess [4, 12]. Unfortunately, there is a fact that access to advanced imaging systems like CT is still limited in developing countries. In our case, CT was not available by the time of hospital admission of the patient. But this was not the unique reason for the inaccurate preoperative diagnosis as pneumoperitoneum presumed to be secondary to perforation of a hollow viscus. Indeed, there are several other causes such as: history of duodenal ulcer, the relatively small size of this liver abscess, and the deficiency of ultrasound scan in case of ruptured liver abscess. By presenting this case of GFPLA, we aimed to highlight the importance of careful examination by the surgeons when abdominal peritonitis and pneumoperitoneum were present without any perforation of a hollow viscus. This case also implied that $\mathrm{CT}$ scan should be performed wherever it is possible to make an early and correct diagnosis of GFPLA which in turn, help to decrease the operative time and improve patient outcomes.

Several studies have reported the cases of successful non-surgical treatment of ruptured pyogenic liver abscess $[11,13]$. In these cases, patients with ruptured liver abscess associated with septic shock and high glycemic level can be successfully treated with percutaneous ultrasound-guided drainage associated with IV broad spectrum antibiotics without surgical intervention. However, these cases had prolonged hospital stay (40-52 days). According to a study of Shiba H., in case of ruptured liver abscess associated with peritonitis and sepsis, drain abscess should not be performed. Instead of that, they cut the part of liver which contained abscess and cleaned the abdominal cavity. Their patient recovered well after surgery without any complication and discharged at the postoperative day 30 [16]. In our case, partial hepatectomy was not conducted to remove the abscess. Alternatively, we firstly performed cleaning of the abscess cavity and removed all the pus inside, in parallel with cleaning of the abdominal cavity. After that, one of the abdominal drainages was directly put inside the abscess. Our patient presented a good recovery without any complication and he was discharged at the 23rd postoperative day. We suggest that this method might be useful for treating ruptured PLA with a single and relatively small size abscess.

In our case, emergency laparotomy was chosen as the first choice following the diagnosis of a secondary peritonitis in order to carry out a careful abdominal lavage. This method also allowed the surgeons to perform cleaning of the abscess cavity and contributed to the successful treatment without partial hepatectomy. Laparoscopy lavage is an alternative option in the treatment of purulent peritonitis but it is associated with a significantly higher rate of reoperations and a higher rate of intra-abdominal abscess [1]. Furthermore, laparoscopic surgery and training is not widely available in the developing countries. Therefore, we suggest that laparotomy might be suitable to combine with the treatment of rupture liver abscess using abdominal drainages.

Finally, $K$. pneumoniae PLA is predominantly seen in Southeast Asia but only few cases have been reported in Vietnam [2, 4]. Strikingly, current researches showed that $K$. pneumoniae infection is becoming an emerging public health problem in Vietnam due to its carbapenem-resistance $[8,14]$. Therefore, further investigations are required to clarify the clinical and paraclinical characteristics of $K$. pneumoniae PLA in Vietnam.

In conclusion, ruptured gas-containing PLA is a lifethreatening complication. It is usually accompanied by peritonitis and pneumoperitoneum and can imitate hollow viscous perforation. In these cases, CT scan should be performed whenever it is possible to make a correct diagnosis. When the abscess has small size, partial hepatectomy might not be necessary and could be replaced by a careful cleaning and drainage of the abscess in association with an appropriate antibiotic therapy.

\section{Abbreviations}

CT: Computed tomography; GFPLA: Gas-forming pyogenic liver abscess; IV: Intravenous; PLA: Pyogenic liver abscess

\section{Acknowledgements}

The authors wish to thank the nursing board of the Emergency Department and the Gastrointestinal Surgery Department of Viet Tiep Hospital, Haiphong, Vietnam for their technical assistance during the 23-day observation of this patient.

\section{Authors' contributions}

TPV and TADD: Management of the case and preparing the manuscript. SVN: Management of the case and critical appraisal and review of the manuscript. NANH: Management of the case and critical appraisal and review of the manuscript. DHH: Management of the case and critical appraisal and review 
of the manuscript. Interpretation of X-rays. All authors read and approved the final manuscript.

\section{Funding}

This work was supported by Haiphong University of Medicine and Pharmacy, Haiphong, Vietnam. The funders had no role in study design, data collection and analysis, decision to publish, or preparation of the manuscript.

\section{Availability of data and materials}

All data generated or analyzed during this study are included in this published article.

\section{Ethics approval and consent to participate}

Ethics approval of this study was given by the Research Ethics Committees of Haiphong University of Medicine and Pharmacy. Authors have agreed to submit it in its current form for consideration for publication in the Journal.

\section{Consent for publication}

Written informed consent for publication of their clinical details and clinical images was obtained from the patient.

\section{Competing interests}

The authors declare that there is no conflict of interest regarding the publication of this article.

\section{Author details}

'Department of General Surgery, Haiphong University of Medicine and Pharmacy, Haiphong, Vietnam. 'Pediatrics Department, Haiphong University of Medicine and Pharmacy, Haiphong, Vietnam.

Received: 3 July 2020 Accepted: 2 September 2020 Published online: 07 October 2020

\section{References}

1. Ceresoli M, Coccolini F, Montori G, Catena F, Sartelli M, Ansaloni L. Laparoscopic lavage versus resection in perforated diverticulitis with purulent peritonitis: a meta-analysis of randomized controlled trials. World J Emerg Surg. 2016;11(1):42. https://doi.org/10.1186/s13017-016-0103-4.

2. Cerwenka H. Pyogenic liver abscess: differences in etiology and treatment in Southeast Asia and Central Europe. World J Gastroenterol. 2010;16(20):245862. https://doi.org/10.3748/wjg.v16.i20.2458.

3. Chiou Y-W, Lin Y-T. Gas-forming Klebsiella pneumoniae liver abscess in a patient without diabetes. J Microbiol Immunol Infect. 2014;48. https://doi. org/10.1016/j.jmii.2014.05.005.

4. Huy H, Tri L, Minh L, Vinh N. Intra-abdominal ruptured liver abscess: computed tomography and clinical features. Med Imaging Radiol. 2019;7:3. https://doi.org/10.7243/2054-1945-7-3.

5. Jun $\mathrm{CH}$, Yoon JH, Wi JW, Park SY, Lee WS, Jung SI, et al. Risk factors and clinical outcomes for spontaneous rupture of pyogenic liver abscess. J Dig Dis. 2015:16(1):31-6. https://doi.org/10.1111/1751-2980.12209.

6. Khim G, Em S, Mo S, Townell N. Liver abscess: diagnostic and management issues found in the low resource setting. Br Med Bull. 2019;132(1):45-52. https://doi.org/10.1093/bmb/ldz032.

7. Lai YC, Su YJ, Chang WH. Ruptured hepatic abscess mimicking perforated viscus. Int J Infect Dis. 2008;12(6):e95-7. https://doi.org/10.1016/j.ijid.2008.06. 005 .

8. Le NK, Hf W, Vu PD, Khu DTK, Le HT, Hoang BTN, et al. High prevalence of hospital-acquired infections caused by gram-negative carbapenem resistant strains in Vietnamese pediatric ICUs: a multi-Centre point prevalence survey. Medicine. 2016;95(27):e4099. https://doi.org/10.1097/MD.0000000000004099.

9. Lederman ER, Crum NF. Pyogenic liver abscess with a focus on Klebsiella pneumoniae as a primary pathogen: an emerging disease with unique clinical characteristics. Am J Gastroenterol. 2005;100(2):322-31. https://doi. org/10.1111/j.1572-0241.2005.40310.x

10. Lee HL, Lee HC, Guo HR, Ko WC, Chen KW. Clinical significance and mechanism of gas formation of pyogenic liver abscess due to Klebsiella pneumoniae. J Clin Microbiol. 2004;42(6):2783-5. https://doi.org/10.1128/ JCM.42.6.2783-2785.2004.

11. Lee KJ, Ryu SH. Ruptured gas-forming pyogenic liver abscess into the peritoneal cavity treated successfully with medical treatment. Korean $J$ Gastroenterol. 2018;71(1):45-8. https://doi.org/10.4166/kjg.2018.71.1.45
12. Lee NK, Kim S, Lee JW, Jeong YJ, Lee SH, Heo J, Kang DH. CT differentiation of pyogenic liver abscesses caused by Klebsiella pneumoniae vs nonKlebsiella pneumoniae. Br J Radiol. 2011;84(1002):518-25. https://doi.org/10. 1259/bjr/23004588.

13. Motoyama T, Ogasawara S, Chiba T, Suzuki E, Yokota H, Haga Y, et al. Successful non-surgical treatment of ruptured pyogenic liver abscess. Intern Med. 2013;52(23):2619-22. https://doi.org/10.2169/internalmedicine.52.0980.

14. Phu VD, Wertheim HFL, Larsson M, Nadjm B, Dinh Q-D, Nilsson LE, et al. Burden of hospital acquired infections and antimicrobial use in Vietnamese adult intensive care units. PLoS One. 2016;11(1):e0147544. https://doi.org/10 1371/journal.pone.0147544.

15. Qian $Y$, Wong CC, Lai $S$, Chen $H$, He $X$, Sun L, et al. A retrospective study of pyogenic liver abscess focusing on Klebsiella pneumoniae as a primary pathogen in China from 1994 to 2015. Sci Rep. 2016;6:38587. https://doi. org/10.1038/srep38587.

16. Shiba H, Aoki H, Misawa T, Kobayashi S, Saito R, Yanaga K. Pneumoperitoneum caused by ruptured gas-containing liver abscess. J Hepato-Biliary-Pancreat Surg. 2007;14(2):210-1. https://doi.org/10.1007/ s00534-006-1136-y.

17. Pham HD, Le QM, Le CT, Vu TMT, Huynh QH, Ho HP, Nguyen QV. Laparoscopic Surgery for Intra-abdominal Ruptured Liver Abscess: A study of 32 cases. Open Access J Surg. 2019:10. https://doi.org/10.19080/OAJS. 2019.10.555798

18. Zizzo M, Zaghi C, Manenti A, Luppi D, Ugoletti L, Bonilauri S. Abdominal wall abscess secondary to spontaneous rupture of pyogenic liver abscess. Int J Surg Case Rep. 2016;25:110-3. https://doi.org/10.1016/j.ijscr.2016.06.026.

\section{Publisher's Note}

Springer Nature remains neutral with regard to jurisdictional claims in published maps and institutional affiliations.

Ready to submit your research? Choose BMC and benefit from:

- fast, convenient online submission

- thorough peer review by experienced researchers in your field

- rapid publication on acceptance

- support for research data, including large and complex data types

- gold Open Access which fosters wider collaboration and increased citations

- maximum visibility for your research: over $100 \mathrm{M}$ website views per year

At BMC, research is always in progress.

Learn more biomedcentral.com/submissions 